\title{
Thromboembolic Disease in Patients with Cancer: 2 Years Descriptive Study in Tinzaparin Treatment
}

\author{
Beatriz Losada ${ }^{1 *}$, D Gutierrez ${ }^{1}$, MV De Torres ${ }^{1}$, I Juez ${ }^{1}$, P Bravo ${ }^{2}$, J Calzas ${ }^{1}$ and JA Guerra ${ }^{1}$ \\ ${ }^{1}$ Department of Medical Oncologists, Fuenlabrada Hospital, Spain \\ ${ }^{2}$ Department of Haematologist, Fuenlabrada Hospital, Spain
}

Submission: August 14, 2017; Published: August 21, 2017

*Corresponding author: Beatriz Losada, Department of Medical Oncologists, Fuenlabrada Hospital, Madrid, Spain, Email: beatriz.losada@salud.madrid.org

\begin{abstract}
Venous thromboembolic disease (VTE) is present in 4-20\% of cancer patients, with a recurrence of $10-17 \%$ in patients treated with anti vitamin $\mathrm{K}$ and 6-9\% with low-molecular weight heparin (LMWH). It delays tumor treatment, causing complications and worsening prognosis within this population. We will describe VTE characteristics (incidence, chemotherapy, complications...) in oncological patients diagnosed between 2012-2014.
\end{abstract}

\section{Introduction}

Venous thromboembolic disease (VTE) appears in 4-20\% of cancer patients. It is the second cause of mortality within first months after tumor diagnosis. VTE is the second most frequent cause of death. Our objective is to describe the factors, complications and recurrences of patients diagnose in our Hospital and to compare our data with described in the literature [1].

\section{Material and Methods}

Retrospective analysis counting 31 patients diagnosed between 2012 and 2014 of VTE (pulmonary thromboembolism, catheter thrombosis or deep venous thrombosis) and treated with therapeutic doses of tinzaparin (LMWH).

\section{Results}

First of all, we have to think about the risk of VTE in these patients. There are risk factors according to neoplasia, treatment ant patient. Risk factors related to neoplasia were lung (11/31), breast (4/31), colon (3/31) and 2 ovary and head/neck. Isolated cases of pancreas, stomach, sarcoma, prostate, peritoneum and unknown origin tumor were also described. According to tumor stage, more than $80 \%$ were metastatic disease. It is well known that stage IV is more prothrombotic than localized disease. Pathological anatomy is also important because adenocarcinoma is usually the most frequent one within VTE and cancer. So, 16/31 were adenocarcinomas, 5/31 epidermoids 2 serous and ductal, isolated cases of lobular, microcytic and non-small cell. In relation to treatment, the most important risk factor was chemotherapy, especially antiangiogenic (7/31). In addition, gemcitabine, platinum, etoposide, and irinotecan are the chemotherapy agents with the highest thromboembolic risk, indeed, in our sample 29/31 had received them [2]. Risk factors associated with the patient were non-oral contraceptives, recent surgery or the elderly population $(12 / 31$ were $>65$ years). $1 / 31$ mutation carried the prothrombin gene. Comorbidities (Charlson Index) are also important. We reached a puntuation of 10 points; however 8 of 10 points were already for neoplasia and metastasis. Another factors to consider were previous admissions. So, $71 \%$ were admitted while $29 \%$ were ambulant (mostly Deep Venous Thrombosis).

Also central catheter was an issue, and 3/31 developed a thrombosis catheter (withdrawal of the same in $2 / 3$ ) and 4 that develop deep venous thrombosis+pulmonary embolism (2 synchronous and 2 metachronous) When we study VTE and cancer, it is very important to know when was the tumor diagnosed because in most of the cases VTE happens in the first months after diagnosis. In our sample, 2 diagnoses of VTE were prior to the discovery of cancer. 1 patient developed VTE 
with two synchronous tumors (breast and endometrium). Also 2 patients with deep venous thrombosis without active disease (head and neck tumors previously). After diagnosis of VTE, treatment should be low-molecular weight heparin. However, the main complication described in the literature is bleeding. In our sample, we have 2 severe bleedings ( 1 cerebral and digestive hemorrhage in two patients with cardiovascular factors, without thrombopenia and anemia). No anemia / thrombopenia secondary to tinzaparin. Only 1 patient had a VTE recurrence after tinzaparin, carrying prothrombin mutation as a risk factor.

\section{Conclusion}

In one meta-analysis is described that early maintenance treatment with LMWH in cancer patients reduces the risk of VTE recurrence in 50\% compared to anti-vitamin $\mathrm{K}$ [3]. Our results are consistent with those of the CATCH study demonstrating the safety of tinzaparin in cancer patients [4]. This study is a small descriptive analysis to identify prognostic factors that can establish risk scales and classify subgroups as the most likely to benefit>6 months with tinzaparin (metastasis, tumor type and treatment) or receive primary-secondary prophylaxis. We can suggest that adenocarcinomas, lung, breast, colon cancer, elderly patients, with comorbidities and in the following months after tumor diagnosis develop more frequently VTE.

\section{References}

1. Halámková J, Penka M (2017) [Current Recommendations for the Prevention and Treatment of Venous Thromboembolism in Cancer Patients]. Klin Onkol 30(2): 100-105.

2. Visvanathan K, Chlebowski RT, Hurley P, Col NF, Ropka M, et al. (2009) American society of clinical oncology clinical practice guideline update on the use of pharmacologic interventions including tamoxifen, raloxifene, and aromatase inhibition for breast cancer risk reduction. J Clin Oncol 27(19): 3235-3258.

3. Ferretti G, Bria E, Giannarelli D, Carlini P, Felici A, et al. (2007) Major bleedings in the comparisons between low-molecular weight heparin versus oral anticoagulant therapy for venous thromboembolism. Thromb Res 119(4): 525-529.

4. Lee AY, Bauersachs R, Janas MS, Jarner MF, Kamphuisen PW, et al. (2013) CATCH: a randomised clinical trial comparing long term tinzaparin versus warfarin for treatment of acute venous thromboembolism in cancer patients. BMC Cancer 13: 284.

\begin{tabular}{l} 
Your next submission with Juniper Publishers \\
will reach you the below assets \\
- Quality Editorial service \\
- Swift Peer Review \\
- Reprints availability \\
- E-prints Service \\
- Manuscript Podcast for convenient understanding \\
- Global attainment for your research \\
- Manuscript accessibility in different formats \\
( Pdf, E-pub, Full Text, Audio) \\
- Unceasing customer service \\
Track the below URL for one-step submission \\
https://juniperpublishers.com/online-submission.php \\
\hline
\end{tabular}

